\title{
ON THE GENERALIZED QUADRATIC GAUSS SUMS AND ITS UPPER BOUND ESTIMATE
}

\author{
JIAFAN ZHANG AND XINGXING LV*
}

Abstract. The main purpose of this paper is to study generalized quadratic Gauss sums, then use the analytic methods, the properties of the classical Gauss sums and character sums to give a sharp upper bound estimate for it. In addition, we also give several interesting fourth and sixth power mean formulae for the sums.

Mathematics subject classification (2020): 11L05, 11L40.

Keywords and phrases: The generalized quadratic Gauss sums, upper bound estimate, the fourth power mean, the sixth power mean, analytic method, computational formula.

\section{REFERENCES}

[1] W. P. Zhang, Moments of Generalized Quadratic Gauss Sums Weighted by L-functions, Journal of Number Theory, 92 (2002), 304-314.

[2] L. CHEn, On the classical Gauss sums and their some properties, Symmetry 2018, 10, 625.

[3] S. M. SHEN AND W. P. ZHANG, The generalized quadratic Gauss sums and its fourth power mean, Mathematics 2019, 7, 258.

[4] A. WeIL, On some exponential sums, Proc. Nat. Acad. Sci. U.S.A., 34 (1948), 203-210.

[5] Z. Y. CHEN AND W. P. ZHANG, On the fourth-order linear recurrence formula related to classical Gauss sums, Open Mathematics, 2017, 15, 1251-1255.

[6] B. C. Berndt And R. J. Evans, The determination of Gauss sums, Bulletin of the American Mathematical Society, 1981, 5, 107-128.

[7] H. BAI AND J. Y. Hu, On the classical Gauss sum and the recursive properties, Advances in Difference Equations, 2018, 2018: 387.

[8] W. P. ZHANG AND J. Y. HU, The number of solutions of the diagonal cubic congruence equation mod $p$, Mathematical Reports, 2018, 20, 73-80.

[9] S. M. SHEN AND W. P. ZHANG, On the quartic Gauss sums and their recurrence property, Advances in Difference Equations, 2017, 2017: 43.

[10] L. Chen And J. Y. Hu, A linear Recurrence Formula Involving Cubic Gauss Sums and Kloosterman Sums, Acta Mathematica Sinica (Chinese Series), 61 (2018), 67-72.

[11] T. T. Wang And G. H. Chen, A note on the classical Gauss sums, Mathematics, 2018, 6, 313.

[12] S. Chowla, J. Cowles AND M. COWLES, On the number of zeros of diagonal cubic forms, Journal of Number Theory, 9 (1977), 502-506.

[13] B. C. BERndT AND R. J. EvAns, Sums of Gauss, Jacobi, and Jacobsthal, Journal of Number Theory, 1979, 11, 349-389.

[14] T. M. Apostol, Introduction to Analytic Number Theory, Springer-Verlag, New York, 1976.

[15] K. IRELAND AND M. Rosen, A classical introduction to modern number theory, Springer-Verlag, New York, 1982. 